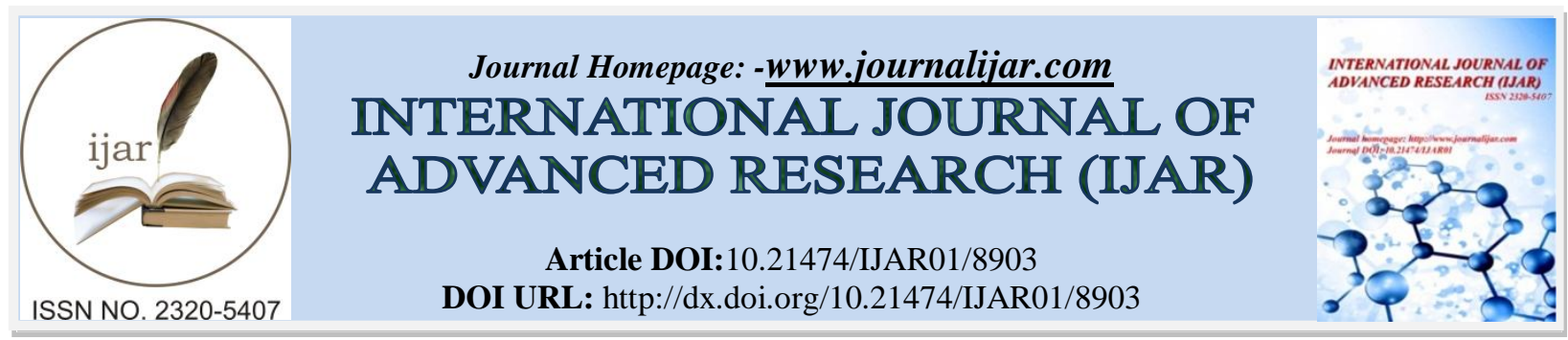

RESEARCH ARTICLE

\title{
HAEMANGIOBLASTOMAS : AN OBSERVATIONAL STUDY OF TWO YEARS IN A TERTIARY CARE CENTRE.
}

\section{Irfan Hussain Bhat ${ }^{2}$, Mohd Iqbal Lone ${ }^{1}$, Nuzhat Samoon ${ }^{3}$, Huzaifa Nazier ${ }^{3}$, Sabiya Paddar ${ }^{4}$, Saba Gul $^{4}$, Shahida Sabreen ${ }^{4}$.}

1. Additional professor, Dept of Pathology, SKIMS, Soura.

2. Post MCH senior resident, Dept of Neurosurgery.SKIMS, Soura.

3. Senoir residents, Dept of Pathology, SKIMS, Soura.

4. PG residents, Dept of Pathology, SKIMS, Soura.

\section{Manuscript Info}

\section{Manuscript History}

Received: 12 February 2019

Final Accepted: 14 March 2019

Published: April 2019

Key words:-

Hemangioblastoma, central nervous system, IHC.

\section{Abstract}

Background: Hemangioblastoma (HB) is a benign, slow-growing, highly vascular tumour of not well defined histological origin. These tumors make up about 1 to 2 percent of all intracranial neoplasms and occur primarily in the posterior fossa. Hemangioblastomas can occur sporadically but in about $20 \%$ to $30 \%$ cases, it is associated with von Hippel-Lindau (VHL) disease. 9 cases of hemangioblastomas were examined with haematoxylin \& eosin (H\&E), reticulin stain and immunohistochemistry where ever needed. Their ages ranged from 12 years to 60 years. All of them were as presented as cystic nodules. The main histological differential diagnosis of Haemaniioblastoma is metastatic clear cell carcinoma. Additionally, because of the cystic mural features, pilocytic astrocytomas of the cerebellum must be separated from haemangioblastomas.

Materials and Methods: The data for the present study was collected from the record section of the department of Pathology of our hospital. Histomorphological and immunohistochemical evaluation of all the cases of hemangioblastomas was done.

Results: In the present study we had 9 cases with 2 of them being recurrent in nature. Age range was 12 to $60 \mathrm{yrs}$ (median: 32 yrs) with Male to Female ratio of 2: 1 (M-6; F-3). Cerebellum was commonest location followed by brain stem.

Conclusion: Hemangioblastomas can occur in throughout the neuroaxis. Cerebellum is the commonest site of occurrence for Haemangioblastoms.

Copy Right, IJAR, 2019,. All rights reserved.

\section{Introduction:-}

The term 'hemangioblastoma' (HB) was introduced by Cushing and Bailey in 1928, occurs in the central nervous system (CNS) and represents 1.5-2.5\% of all the intracranial neoplasms.[1,2] As per the current WHO CNS tumors classification, it is a grade I tumor. They are usually infratentorial; cerebellum around the fourth ventricle is the commonest site of occurrence and supratentorial location is lesser common. Other very rare extracerebellar sites of 
occurrence include spinal cord (more commonly medulla, spinal roots including cauda equina), brain stem, optic nerve, retina and craniospinal meninges.[3-7] HBs may be associated with von Hippel-Lindau (VHL) disease, which is an autosomal dominant disease. Histologically, HBs are characterized by rich vascularity, typically consisting of capillary-sized blood vessels separated by intervascular stromal cells (SCs). These tumors are still regarded as 'neoplasms of uncertain histogenesis. Though the histological origin of the SCs is not yet fully characterized but has been shown to be the neoplastic cells. Moreover, it has been now shown that tumorigenesis of HBs depends on mutational inactivation of VHL tumor suppressor gene.[8] Few studies even suggested VHL gene regulation of tumor angiogenesis by negative regulation of vascular endothelial growth factor (VEGF) expression.[9-11].

\section{Material and Methods:-}

The data for the present study was collected from the record section of the department of Pathology of our hospital. Two year period from January 2017 to January 2019 was taken for the present study. A total no. of 9 cases were evaluated. Information about age, gender, tumor location and tumor size were determined for each case of haemangioblastoma.

\section{Results:-}

In the present study a total no. of 9 cases were evaluated. The age of the patients ranged from 12 to $60 \mathrm{yrs}$, and a mean age was 36yrs. The male to female ratio was 2:1. The patients presented with headache, neck pain and vomiting. The cerebellum being the most common site (7cases $/ 77.78 \%$ ), and it was followed by the brain stem (2cases/22.22\%). Recurrent hemangiomablastomas (figure 1) were seen in 2 cases $/ 22.22 \%$ ). Radiologically haemangioblastomas show solid (mural nodule) -cystic component. (Fig 1) In the histopathological examination, the tumor sections showed large and vacuolated stromal cells and numerous arborizing capillary-size blood vessels (fig 2). Vimentin was strongly positive both stromal cells and blood vessels in all tumors. CD34 immunostaining highlighted the arborizing and complex vascular network, whereas the tumor stromal cells were negative (fig 3). Stromal cells showed positivity for S100 (fig 4).

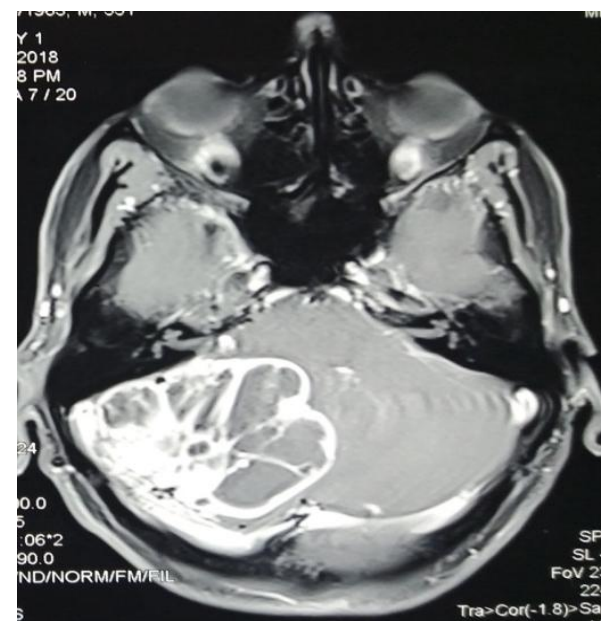

Figure 1:-This radiographic image of a male patient shows Solid cystic changes in a recurrent haemangioblastoma.

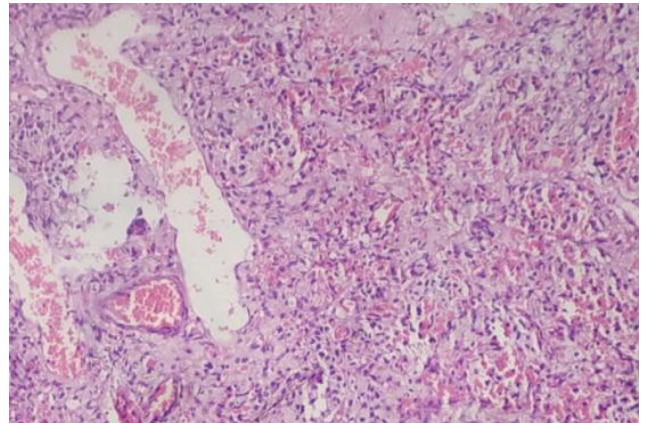

Fig 2:-Photomicrograph of the tumor sections shows large and vacuolated stromal cells and numerous arborizing capillary-size blood vessels.( H\&E,100X). 


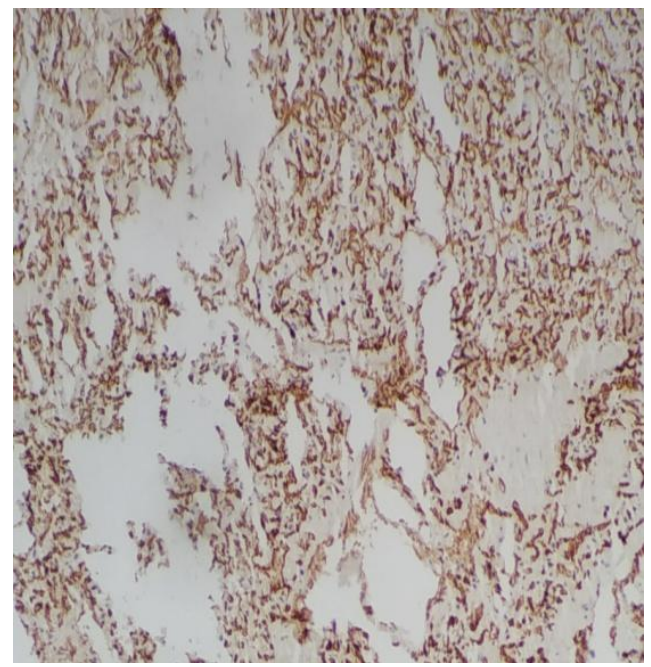

Fig 3:-Photomicrograph shows blood vessels of hemangioblastoma positive for CD34. (IHC 100X)

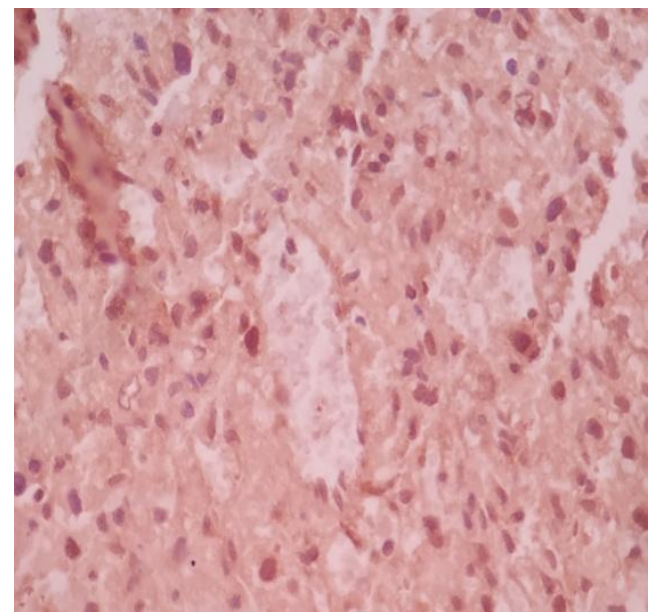

Fig 4:-Photomicrograph shows stromal cells of the tumor positive for S100 (IHC 400X)

\section{Discussion:-}

Capillary hemangioblastoma is a slowly growing tumor which usually has cystic features morphologically (12). On computerized tomography (CT), it is recognized as a contrast-enhancing nodule because of its cystic features (13, 14,15). The symptoms are associated with the progressively growing cystic component of the tumor. In some cases, as a result of the erythropoetin secretion from the vascular endothelial cells of the tumor, polycythemia becomes apparent (12-14). Macroscopically, hemangioblastoma is a well-circumscribed tumor which has both solid and cystic components $(14,16)$. The solid component, so called the mural nodule shows contrast enhancement on CT and prominent vascular features on angiography. Macroscopically, the tumor has a bright yellow color as a result of its lipid content (13-15). The histological features are rather original consisting of 2 components. These components are the capillary network lined by hyperplastic endothelial cells and the stromal cells which have pleomorphic or lobulated nuclei and lipid containing abundant, pale cytoplasms (13-15, 17). Mitoses are usually inapparent $(13,14)$ the origin of the stromal cells is controversial. The expression of growth factors and growth factor receptors have been studied by Böhling et al. (18), and it has been found that the stromal cells express abundant epidermal growth factor receptor (EGFR) and some platelet-derived growth factor receptor-alpha (PDGF-alpha). It was concluded that the expression of highly angiogenic growth factors and their receptors might contribute to the rich vascularity of the tumor. The stromal cells reveal immunoreactivity for cytokeratin, vimentin, neuron-specific enolase (NSE), S-100 protein, glial fibrillary acidic protein (GFAP), epithelial membrane antigen (EMA) and actin, but are negative with F-VIII/von Willebrand's factor (13-15,19). On the other hand, the relation between angiogenesis and tissue expression of vascular endothelial growth factor (VEGF) has been studied by Vaquero J et al. (20) and it has been 
found that the number of intratumoral microvessels, identified by the endothelial marker CD 34, does not correlate with the degree of VEGF expression. This finding suggests that endothelial growth factors other than VEGF may regulate tumor angiogenesis in these neoplasms. Especially the immunoreactivity with vimentin, GFAP, EMA and cytokeratin is almost identical to the reactivity pattern of meningotheliomatous TUNA et al. 173 meningioma and so the possibility of the stromal cells of hemangioblastoma to derive from the arachnoid cells of meningotheliomatous meningiomas by cellular degeneration has been considered (21). Although there are many different views about the histogenesis of the stromal cells, its exact origin is still not clear. In both of our cases, hematoxylen-eosin stained sections were sufficient for the diagnosis. The immunohistochemical stains were applied to support the diagnosis. In the differential diagnosis of capillary hemangioblastoma, metastatic renal cell carcinoma must be considered. Renal cell carcinoma shows necrosis, mitoses and cytokeratin, vimentin and EMA immunoreactivity, which are important clues in distinction (13-15). It is also suggested that the AgNOR method is a useful adjunct in achieving the differential diagnosis of hemangioblastoma and renal cell carcinoma in the nervous system (22). Anaplastic astrocytoma and meningioma also show similarity to the tumor (23). In the study, in which cytologic features of hemangioblastoma are compared with meningioma, anaplastic astrocytoma and renal cell carcinoma intraoperative smears were evaluated and concluded that smears of hemangioblastomas are cellular and cohesive, the cytoplasmic borders are indistinct and the nuclei are hyperchromatic and mildly pleomorphic. Smears of meningiomas, anaplastic astrocytomas and renal cell carcinomas are more discohesive than those of hemangioblastomas. The cells of renal cell carcinoma show distinct cellular borders while in astrocytoma there is prominent cytoplasmic fibrillarity (23). Another lesion which must be considered in the differential diagnosis is angioglioma (14, 24). In angioglioma the neoplastic astroglial cells are scattered among the vascular structures and usually the glial component is prominent (24). Capillary hemangioblastomas may be multiple $(13,25)$. As a conclusion, capillary hemangioblastomas are biologically slowly growing lesions which have cystic and solid (mural) features morphologically. The symptoms are associated with the progressively growing cystic component of the tumor. Hemangioblastomas show very good prognosis with sufficient surgical excision, but with insufficient excisions recurrences are inevitable as was seen in two cases of our study.

\section{Conclusion:-}

Hemangioblastomas can occur in throughout the neuroaxis. Cerebellum is the commonest site of occurrence for Haemangioblastoms.

\section{Conflict of interest:}

None

\section{Funding:}

None

\section{Refrences:-}

1. Cushing H, Bailey P. Tumours arising from the blood vessels of the brain. Angiomatous malformations and Haemangioblastomas. London: Bailliere. Tindall and Cox; 1928.

2. Aldape KD, Plate KH, Vortmeyer AO, Zagzag D, Neumann HPH. Haemangioblastoma. In: Louis DN, Ohgaki H, Wiestler OD, Cavenee WK, editors. WHO Classification of tumours of the Central Nervous System. 4th Ed. Lyon, France: IARC; 2007. p.184-6.

3. Kepes JJ, Slowik F. Arvid Lindau's cerebellar hemangioblastoma 70 years later. Some pediatric aspects. Ann N Y Acad Sci 1997;824:112-3.

4. Aickalin MF, Oner U, Tel N. Supratentorial haemangioblastoma: A case report and review of the literature. Arch Pathol Lab Med 2003;12:e382-4.

5. Neumann HP, Eggert HR, Weigel K, Friedburg H, Wiestler OD, Schollmeyer P. Hemangioblastomas of the central nervous system. A 10-year study with special reference to von Hippel-Lindau syndrome. J Neurosurg 1989;70:24-30.

6. Richmond BK, Schmidt JH. Congenital cystic supratentorial hemangioblastoma. Case report. J Neurosurg 1995;82:113-5.

7. Rubio A, Meyers SP, Powers JM, Nelson CN, de Papp EW. Hemangioblastoma of the optic nerve. Hum Pathol 1994;25:1249-51. 
8. Vortmeyer AO, Gnarra JR, Emmert-Buck MR, Katz D, Linehan WM, Oldfield EH, et al. von Hippel-Lindau gene deletion detected in the stromal cell component of a cerebellar haemangioblastoma associated with von Hippel-Lindau disease. Hum Pathol 1997;28:540-3.

9. Hussein MR. Central nervous system capillary haemangioblastoma: The pathologist's viewpoint. Int J Exp Pathol 2007;88:311-24.

10. Wykoff CC, Pugh CW, Harris AL, Maxwell PH, Ratcliffe PJ. The HIF pathway: Implications for patterns of gene expression in cancer. Novatis Found Symp 2001;240:212-25.

11. Hatva E, Böhling T, Jääskeläinen J, Persico MG, Haltia M, Alitalo K. Vascular growth factors and receptors in capillary hemangioblastomas and hemangiopericytomas. Am J Pathol 1996;148:763-75.

12. 12.McKeever PE. Central Nervous System. In: Sternberg SS, Antonioli DA, Carter D, et al. editors. Diagnostic Surgical Pathology. 3rd ed. Philadelphia: Lippincott William\&Wilkins, 1999; 411-60.

13. Parici EJ, Mena H. Nonglial Tumours. In: Nelson JS, Parisi JE, Schochet SJr, editors. Principles and Practice of Neuropathology. St. Louis: Mosby, 1993; 203-66.

14. Namiki H, Hardman MJ, Yang H. The Central Nervous System. In: Silverberg SG, Delellis RA, Frable WJ, editors. Principles and Practice of 174 CEREBELLAR HEMANGIOBLASTOMA Surgical Pathology and Cytopathology. 3rd ed. Churchill and Livingstone, 1997; 2905-3036.

15. Rosenbium MK. Neuromuscular System: Central Nervous System. In: Rosai J, editor. Ackerman’s Surgical Pathology. 8th ed. New York: Mosby, 1996;2227-65.

16. Giannini C, Scheithauer BW, Hellbuch LC. Peripheral nerve hemangioblastoma. Mod Pathol 1998;11:9991004.

17. Böhling T, Maenpaa A, Timonen T, et al. Different expression of adhesion molecules on stromal cells and endothelial cells of capillary hemangioblastoma. Acta Neuropathol 1996;92:461-6.

18. Böhling T, Hatva E, Kujala M. Expression of growth factors and growth factor receptors in capillary hemangioblastoma. J Neuropathol Exp Neurol 1996; 55(5): 522-7.

19. McComb RD, Jones TR, Pizzo SV, et al. Localisation of factor VIII/von Willebrand factor and glial fibrillary acidic protein in the hemangioblastoma: implications for stromal cell histogenesis. Acta Neuropathol 1982;56:207-13.

20. Vaquero J, Zurita M, Coca S. Expression of vascular endothelial growth factor in cerebellar hemangioblastomas does not correlate with tumor angiogenesis. Cancer Lett 1998;132:213-7.

21. Mizuno J, Iwata K, Takei Y. Immunohistochemical study of hemangioblastoma with special reference to its cytogenesis. Neurol Med Chir 1993;33:420-4.

22. Crocker J, Carey MP, Allcock R. Hemangioblastoma and renal clear cell carcinoma distinguished by means of the AgNOR method. Am J Clin Pathol 1990;93:555-7.

23. Commins DL, Hinton DR. Cytologic features of hemangioblastoma: comparison with meningioma, anaplastic astrocytoma and renal cell carcinoma. Acta Cytol 1998;42:1104-10.

24. Bonnin JM, Pena CE, Rubinstein LJ. Mixed capillary hemangioblastoma and glioma. A redefinition of the "angioglioma". J Neuropathol Exp Neurol 1983;504-16.

25. Gumprecht H, Lumenta CB. Multifocal hemangioblastoma in a young woman with von Hippel-Lindau syndrome. Neurochir 1998;59:181-4. 